\title{
A Critical Discourse Analysis of Reports about China on the COVID-19 Pandemic in The New York Times
}

\author{
Junfang Mu1, Hongyue Zhao1, Guang Yang2 \\ ${ }^{1}$ College of Foreign Languages, Hebei University, Baoding, China \\ ${ }^{2}$ The State Key Laboratory of Alternate Electrical Power System with Renewable Energy Sources, North China Electric Power \\ University, Baoding, China \\ Email: Junfangmu@163.com
}

How to cite this paper: $\mathrm{Mu}, \mathrm{J} . \mathrm{F} ., \mathrm{Zhao}$, H.Y. and Yang, G. (2021) A Critical Discourse Analysis of Reports about China on the COVID-19 Pandemic in The New York Times. Open Access Library Journal, 8: e7746. https://doi.org/10.4236/oalib.1107746

Received: July 9, 2021

Accepted: August 1, 2021

Published: August 4, 2021

Copyright $\odot 2021$ by author(s) and Open Access Library Inc.

This work is licensed under the Creative Commons Attribution International License (CC BY 4.0)

http://creativecommons.org/licenses/by/4.0/

\begin{abstract}
The coronavirus disease 2019 (COVID-19) pandemic is a hot topic in 2020. Through the critical discourse analysis of related reports about the pandemic in China in The New York Times, ideology in media behind the news reports and China's image can be revealed. Based on Norman Fairclough's three-dimensional framework, combined with the methods of quantitative analysis, qualitative analysis and corpus analysis, and with the help of the corpus analysis software AntConc, this thesis makes an in-depth analysis of 35 news reports in The New York Times from September to December of 2020 from three dimensions: description, interpretation and explanation. The description level analyzes the text according to keywords and concordance lines; the interpretation level analyzes from the perspective of news sources and reporting modes; and the explanation level analyzes from the aspects of institutional context and societal context. Through the thorough analysis of the news reports, the thesis finds that The New York Times compliments China's outcome of fighting against COVID-19, but doesn't fully agree with the measures. Besides, The New York Times puts China on the opposite side of the United States and other western countries, and it regards China as a threatening and autocratic country to a certain extent. This thesis is of avail not only to contribute to researches in the field of CDA, especially investigations of news reports based on corpus, but also is useful for readers to understand news reports objectively when they read news coverage of the COVID-19 pandemic about China, and then to objectively view the construction of China's image in foreign mainstream media.
\end{abstract}

\section{Subject Areas}

Linguistics 


\section{Keywords}

Critical Discourse Analysis, The COVID-19 Pandemic, The New York Times

\section{Introduction}

Breaking out in Wuhan, Hubei province, China in December, 2019, coronavirus disease 2019 (COVID-19) is infectious and fatal, just as the widespread severe acute respiratory syndrome (SARS) that broke out in China 18 years ago, which attracts considerable attention at home and abroad. Mainstream media in the domestic and overseas track and report the incident, including The New York Times. The New York Times, a daily published newspaper, is one of the mainstream newspapers in the United States. It is issued all around the world, and maintains extensive influence. However, in recent years, studies in the field of CDA show that some reports on China in The New York Times are mixed with media's ideology and build a relatively negative image of China. Liu (2012) [1] deems that it manipulates its audience by applying discourse strategies in China's news stories such as quoting words of witnesses, achieving a balance in reported speech and so on, which show disguised objectivity, and through which a negative even tyrannical image of China is constructed. Besides, when reporting on Sino-US trade war, The New York Times takes into consideration the power relation between the United States and China, American interests, and so on ([2], p. 85). In addition, negative words, semi-specific sources, etc. are employed, constructing a negative image of China, an unfavorable country ([2], p. 85). During the period from September to December of 2020 when the pandemic situation is stable at home, The New York Times reports the pandemic from the perspective of public health to economics, social life and diplomacy. Various aspects of news reports are helpful to analyze the hidden ideology and the construction of China's image. Besides, 2020 is a tough year for China to fight against the pandemic, and also a key year to achieve the first centenary goal. In the fourth quarter of 2020, the fifth plenary session of the 19th CPC Central Committee makes a two-stage overall arrangement for the second centenary goal, which is of overall and historic significance. Therefore, it is of great value to analyze China's COVID-19 pandemic reports from September to December in The New York Times under this background.

This thesis will select COVID-19 news reports about China from September to December of 2020 in The New York Times as data to construct a small corpus, process the data through corpus analysis tool AntConc 3.5.9 (windows) 2020, and then conduct an analysis based on Fairclough's three-dimensional framework from three stages of description, interpretation and explanation. The data collection process is as follows. Through searching "China" and "COVID" from September to December in The New York Times, which is included in the Dow Jones Factiva database, nearly one thousand reports covering various aspects are 
found. Then remove repetitive reports and irrelevant reports such as those about other countries and those about other domestic events, for example, the obesity rates in China, which just mention China and the pandemic but are irrelevant to the topic of the thesis. This procedure is done by manual screening. In this way, thirty-five highly related reports are singled out. Then in order to get clean files, delete redundant information such as the type, the number of words, the name of reporter, etc. and delete redundant symbols such as paragraph marks. After that, convert these characters into one plain text, with "txt" as extension. Finally, build a small corpus called Corpus $\mathrm{N}$ which contains 42,824-word tokens and 5955-word types.

Through analyzing the reports of COVID-19 about China, the thesis tries to explore the linguistic features of these reports, to reveal the ideology behind these linguistic features, and to reveal the image of China that the media construct.

\section{Literature Review}

The quantity of studies about the COVID-19 pandemic increases with time. However, the quantity of that about news reports is limited by far, with only several dozens.

\subsection{Previous Studies of News Reports on the COVID-19 Pandemic in Linguistics}

The researches of news reports on the COVID-19 pandemic primarily focus on cognitive linguistics, especially from the perspective of metaphor theory. A few studies focus on semantics and systemic functional linguistics. Among them, the corpus linguistics research method is partly applied.

On the basis of criticizing traditional war metaphors in the COVID-19 pandemic reports, Dong (2020) [3] expounds the meaning of metaphor framing in western media at various levels, and analyzes various alternative metaphors in detail. The paper provides guidance and suggestions for selecting optimal metaphors in a specific context, and is helpful to understand and respond to the COVID-19 pandemic actively and effectively. Luporini (2021) [4] focuses on the headings and subheadings of the COVID-19 pandemic reports from the perspective of Applying Conceptual Metaphor Theory and Systemic Functional Linguistics, with the help of the corpus method. Luporini finds resemblances of the virus metaphorical conceptualization, as well as some significant differences in framing. For example, compared with China Daily, the metaphors of virus in The Wall Street Journal are negative, which further lead to a negative image of China. As for semantics, Chen \& Xie (2020) [5] classify the usage of linguistic hedges in different aspects of COVID-19 reports in the English version of People's Daily. Ge (2020) [6] conducts a corpus-based analysis on COVID-19 reports about China from January 7 to March 10. It reveals the discourse representation and ideology of The New York Times related reports from an empiri- 
cal perspective, and finds that a relatively negative image of China is built in The New York Times. However, it doesn't refer to the situation in the latter half of 2020. Besides, the research only adopts the corpus method, analyzing key words and concordance lines, which leaves space for other studies to expand.

\subsection{Previous Studies of News Reports on the COVID-19 Pandemic Based on CDA}

The quantity of studies in the field of CDA about news reports on COVID-19 is inadequate, especially of that about China under the circumstances that COVID-19 situation is relatively stable.

Chaiuk \& Dunaievska (2020) [7] find that the fear culture has a significant impact when British media report news on COVID-19. Although COVID-19 is lethal and irresistible to a certain extent, intensive reports and some dramatic descriptions indeed cause anxiety to readers in some degree, from which can be inferred that the media's ideology has a profound influence on the public. Through analyzing the reports of Australian media, Sun (2021) [8] discovers that the efforts of China are framed into different terms according to different sorts of newspapers, but they all embody the discourse of "China threat" and "Chinese influence". However, the study is conducted only within reports, without considering social context and so on. Feng \& Wang (2020) [9] analyze the reports from The Wall Street Journal through combining Multimodal Discourse Analysis and CDA, and find that the mainstream newspaper is not objective when it constructs the image of China. However, only one newspaper is not very representative of mainstream newspapers.

Some researchers use Fairclough's three-dimensional framework to conduct analyses. Zhao (2021) [10] analyzes 180 reports from January to February in People's Daily, and finds that People's Daily adopts the positive attitude towards the pandemic and society, and it plays a great role in guiding public opinion. However, it simply analyzes one domestic newspaper, and doesn't mention foreign media.

Through reviewing researches about news reports on the COVID-19 pandemic, some deficiencies are found. Firstly, analyses about China's image under this topic are not comprehensive. Secondly, studies of foreign media based on $\mathrm{CDA}$ are few, and studies of American media mainly concentrate on The Wall Street Journal. Lastly, there are hardly any relevant studies involving reports in the later half of 2020, during which the pandemic is under control within China but still affects people's lives, economics, and so on, and which the fifth plenary session of the 19th CPC Central Committee is held. This thesis selects thirty-five representative news reports from September to December of 2020 in The New York Times to analyze the ideology of the media and China's image, which attempts to be a supplement to the above researches, especially to contribute to enrich researches in the field of CDA about the COVID-19 pandemic in the later part of 2020. Besides, this thesis combines the corpus method, trying to provide 
a relatively objective study.

\section{Theoretical Background}

Derived from Critical Linguistics (CL), CDA is first mentioned in Language and Power by Norman Fairclough (1989) [11]. It focuses on the relationship between discourse and society, and the relationship between discourse and ideology. Representatives in the field of CDA are Norman Fairclough, Van Dijk, Ruth Wodak, and so on. Among them, Fairclough is influential to a certain extent. This chapter introduces the development and key concepts of Fairclough's three-dimensional framework, as well as the content of it, aiming at providing the thesis with a theoretical background.

\subsection{Development and Key Concepts of Fairclough's Three-Dimensional Framework}

In the article On Fairclough's Theory of Critical Discourse Analysis, Ji \& Xin (2009) ([12], p.23) concludes three phases of Fairclough's theory of CDA, with "power and ideology", "discourse and social changes", and "globalization" as the goal respectively. Fairclough (1989) ([11], p.25) firstly proposes a three-dimensional framework in Language and Power as an analyzing method: discourse as text, interaction and context. Fairclough (1989) ([11], p.24) regards language as discourse and as social practice, and he proposes that discourse is "the whole process of social interaction", which includes not only the text, but also the process of production and the process of interpretation. Thus, three elements of discourse are involved: text, communication and social context. According to these three elements of discourse, Fairclough puts forward three stages of CDA correspondingly: description, interpretation and explanation.

The second phase of Fairclough's theory takes discourse and social change as the goal. He perceives the discourse events as text, the example of discourse practice and the example of social practice, which provides a three-dimensional model to research: text, discursive practice and social practice (Liu, 2020) [13]. The third phase of Fairclough's theory takes globalization as the goal. He further perfects his framework and it develops into a relatively perfect tool to conduct analysis in the field of CDA, which includes stages of description, interpretation and explanation.

Three concepts have to be mentioned here: discourse, power and ideology. Fairclough (1989) ([11], p.17) puts forward that the conception of language is discourse which is as social practice determined by social structure. In this thesis, discourse is the written language about reports on China's COVID-19 pandemic. Another concept is power. It is closely related to discourse. "Power is exercised and enacted in discourse" and "there are relations of power behind discourse" ([11], p.73). It is implicit instead of explicit. Besides, power is exercised through ideology ([11], p.2). According to Fairclough (1989) ([11], p.2), ideologies are "common-sense" assumptions which are "implicit in the conventions 
according to which people interact linguistically, and of which people are generally not consciously aware". That is to say, it is implicit and almost imperceptible, but does exist extensively. To sum up, discourse, ideology and power are three closely related key concepts.

\subsection{The Content of Fairclough's Three-Dimensional Framework}

The framework of discourse analysis is presented in Figure 1. In the framework, there are three stages of $\mathrm{CDA}$, namely description, interpretation, and explanation.

Description is "the process of production, of which the text is a product" ([11], p.24) It is a process of analyzing the features in a text. Fairclough provides three levels of the text: vocabulary, grammar and textual structures. Under each of the three levels, there are ten questions to elaborately analyze the details, mainly focusing on three values. Experiential values focus on "the producer's experience of the natural and social world" ([11], p.110). It investigates the classification of words, and the ideologies behind words. Relational values of words discuss the interrelation between the choice of words and the social relationship between participants. It analyzes words' euphemisms and formalities. Expressive values concern subjects and social identities ([11], p.112). This thesis will not adopt the whole part of the description process, but put emphasis on the vocabulary. Besides, the corpus method will be employed to assist the study of the vocabulary in the text.

The stage of interpretation is about the relationship between text and interaction. There are two phases involved in the stage of interpretation: participants' processes of text production, which regards the text as "the product of a process of production"; and text interpretation, which regards the text as "a resource in the process of interpretation" ([11], p.26). As for producing news reports, news sources and reporting modes can be analyzed. News reporters construct discourse by quoting information from different sources, and convey their views and attitudes directly or indirectly. By analyzing the sources of news discourse, the relationship between discourse and ideology can be revealed. Besides, different specific degrees of news sources are helpful to analyze ideologies of media.

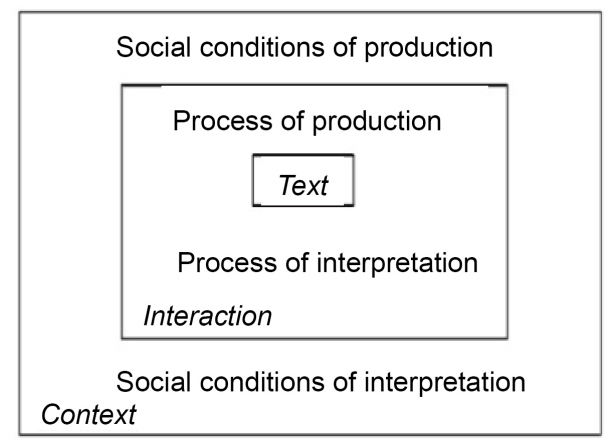

Figure 1. Discourse as text, interaction and context ([11], p.25). 
What's more, reporting modes of 35 reports are examined to keep on discussing ideologies.

According to Fairclough (1989) ([11], p.163), "explanation is a matter of seeing a discourse as part of processes of social struggle, within a matrix of relations of power". It is aimed at depicting a discourse as one section of a social process, to show the mutual effect between discourse and social structure. Members' resource (MR) refers to "the presentation that you have stored in your memory", both the linguistic and the non-linguistic things ([11], p.11). On the one hand, power relations have effects on members' resource which will further influence producing discourse. On the other hand, the interpretation of the discourse will also affect members' resource which will influence the future social structures. Therefore, there are two phases involved in the stage of explanation: social determinants of discourse as well as social effects of discourse. On each of these two levels, there are three levels of social organization. They are the societal level, the institutional level, and the situational level. In this thesis, the societal level and the institutional level are analyzed.

\section{An Analysis of Reports in The New York Times about China on the COVID-19 Pandemic Based on CDA}

This chapter will conduct an analysis of the news reports on the COVID-19 pandemic in The New York Times with Fairclough's three-dimensional framework.

\subsection{Description of Reports about China on the COVID-19 Pandemic}

Description is the first stage of Fairclough's CDA. In this stage, keywords and concordance analyses will be conducted.

\subsubsection{Keywords Analysis}

According to Scott (qtd. in Ge 2020) ([6], p.110), the "keywords" in corpus linguistics refer to the words of which frequency is significantly higher than the corresponding words in the reference corpus. By analyzing the keywords of the Corpus N, the thematic features of these reports in The New York Times can be found. This thesis chooses the Brown Corpus as the reference corpus when analyzing the keywords. The Brown Corpus, the full name of which is The Brown University Standard Corpus of Present-Day American English, is a general language corpus of modern American English for digital computers. It was compiled by Henry Kučera and W. Nelson Francis at Brown University in the 1960s. There are almost one million words; in addition, the texts in the corpus are taken from newspapers, books and government documents on different subjects, the numbers of which add up to nearly five hundred. Therefore, it is large enough and relatively accurate to be used as a reference corpus in this process.

By comparing the reference corpus in AntConc, nearly 600 keywords are obtained. Then remove the functional words such as "the", "that", "on", and select 
the top 100 keywords. After that, classify these keywords and make a chart as shown in Table 1.

According to Table 1, keywords about "people" and "place" account for a large proportion, especially the line of "people". The classification of "people" can be further divided into three categories. The first category is the specific people, which is shown as the family name, such as Zhang, Zhong, Gao, Li. The second category is people in groups, including the general groups such as Chinese, people, workers, residents, public, travelers, students; and the specific groups, such as experts, scientists, professors, companies (company), media, doctors, Pfizer, Sinopharm, Sinovac. The third category of people is related to government such as Xi Jinping, officials (official), government, Trump, party, authorities(authoritarian), communist, agency, Biden, leader. These three categories in the line of "people" cover the most sorts of people in a society, which shows the fairness of The New York Times to a certain degree when referring to someone. Besides, two points are worth mentioning. Firstly, pharmaceutical companies from China and America can be noticed in the second categories, including Pfizer, Sinopharm, Sinovac, which can be deduced that the description object turns a little to the treatment of disease. Secondly, the proportion of people related to the government is prominent, which reflects that the focus of The New York Times includes the activities of government and authorities.

Apart from the majority of keywords mentioned above, four lines about COVID-19 account for a large proportion, including "virus and disease", "action", "prevention and control", and "influence and effect", which add up to one third of the total keywords listed. In the line of "influence and effect", "global" and "world" represent the scope of the influence; and "health", "economy", and "exports" represent the aspects of the influence, which manifest that COVID-19

Table 1. Top 100 keywords of corpus N.

\begin{tabular}{|c|c|c|}
\hline Classification & Keywords & Percentage \\
\hline Place & $\begin{array}{l}\text { China, Beijing, Wuhan, country (countries), Shanghai, the United States, province, internet, online, } \\
\text { Hangzhou, city, local, foreign, emirates, hospitals, university, Hong Kong, software, Twitter }\end{array}$ & $19 \%$ \\
\hline People & $\begin{array}{l}\text { Chinese, Xi Jinping, people, officials (official), government, Zhang, Trump, party, workers, experts, } \\
\text { scientists, public, companies (company), professor, authorities (authoritarian), residents, communist, } \\
\text { media, Pfizer, Sinopharm, Sinovac, Zhong, Gao, Li, Wang, doctors, travelers, agency, Yan, Guo, } \\
\text { Bannon, Biden, students, Jan, leader }\end{array}$ & $35 \%$ \\
\hline Time & Months (month), year & $2 \%$ \\
\hline Event & news, outbreak, lockdowns, cases & $4 \%$ \\
\hline Virus and disease & virus, coronavirus, pandemic, COVID, infections, disease, IgM, SARS, infected & $7 \%$ \\
\hline Prevention and control & trials, strategy, vaccine (vaccines, vaccinated), control, doses, masks & $6 \%$ \\
\hline Influence and effect & health, global, economy, exports, emergency, results, late, emerged, world, spread, new, quickly, & $12 \%$ \\
\hline Number & percent, million (millions), many, more & $4 \%$ \\
\hline
\end{tabular}


spreads widely and permeates deep into various fields of life. The sum of the proportion of "action" line and "prevention and control" line is $14 \%$, which is more than the proportion of "virus and disease" line, which to some extent proves agreement of The New York Times about China's efforts to fight against the pandemic, and about China's effective measures.

\subsubsection{Concordance Analysis}

Through analyzing concordance about keywords, more in-depth details can be found, making the analysis of keywords more objective. Because of the large number of keywords, this thesis only selects two of them as node words: "China" and "COVID", which are highly related to the thesis's topic. Using corpus software AntConc to search node words "China" and "COVID" respectively, a total of 529 and 57 lines are found correspondingly. Randomly select 10 lines in each of these two results. Table 2 and Table 3 show part of these concordance lines.

Table 2. Concordance lines of "China".

\begin{tabular}{|c|c|}
\hline 1 & China aims to end extreme poverty, but COVID-19 exposes gaps. \\
\hline 2 & China bore responsibility for the coronavirus outbreak in the United States. \\
\hline 3 & China has lost 0.34 per 100,000 , or about 4,750 people. \\
\hline 4 & $\begin{array}{l}\text { Unlike the Trump administration, which has said it is prioritizing opening the economy while essentially giving up on } \\
\text { controlling the pandemic, China moved aggressively to stop the virus. }\end{array}$ \\
\hline 5 & China, please do not invade us right now. We aren't who we used to be. \\
\hline 6 & China still has been vastly better at protecting its people than the United States. \\
\hline 7 & But China now represents the extreme, Communist version of a highly managed. \\
\hline 8 & China's resurgence has infuriated President Trump, who spent months blaming Beijing for... \\
\hline 9 & $\begin{array}{l}\text { China saw millions of its citizens flocking to bus stations, train stations and airports to travel all across their country for a } \\
\text { national holiday. }\end{array}$ \\
\hline 10 & China is manipulating online discourse to enforce the Communist Party's consensus. \\
\hline
\end{tabular}

Table 3. Concordance lines of “COVID”.

\footnotetext{
1 The contrast between the current state of the United States and China, especially about COVID and the economy, has got to be a huge resource for $\mathrm{Xi}$ in terms of domestic support.

2 China gives unproven COVID-19 vaccines to thousands, with risks unknown.

3 Authoritarian Strategy: Effective, but Suffocating. China's approach to keep COVID-19 at bay has helped restore confidence and allowed businesses to reopen.

4 Now, as a new COVID-19 wave engulfs Europe and the United States, the organization is in the middle of a geopolitical standoff between the world's two greatest powers, the United States and China.

5 China aims to end extreme poverty, but COVID-19 exposes gaps.

6 China's early efforts to fight the spread of COVID-19, including lengthy lockdowns across broad areas of the country, left rural residents stranded hundreds of miles from the factories where they work.

7 Party propaganda has asserted that China's success in extinguishing COVID-19 infections shows its overall “institutional superiority."

8 China Peddles Falsehoods to Obscure Origin of COVID Pandemic. To push the idea that the virus didn't come from China, the government has misrepresented experts' remarks and given dubious theories...

9 By some measures, China is leading the global race for a COVID-19 vaccine

10 Alas, we aren't who we think we are. COVID-19 was supposed to be China's Chernobyl. It's ended up looking more like the West's.
} 
The concordance lines of the word "China" from Corpus $\mathrm{N}$ show that The New York Times focuses on the impact and outcomes of the pandemic control about the COVID-19 pandemic in China from September to December of 2020, and reports relatively objective coverage, such as the number of deaths per one hundred thousand people and the travel of people to all parts of the country. The New York Times sees the efforts and the consequence of China fighting against COVID-19, and expresses that China does better than the United States in protecting people. However, to describe China, the newspaper uses negative words such as "manipulating", and "invade", which reflects that The New York Times mixes its attitude when reporting relevant news. It considers China a threatening country. In this way, it guides public opinion, and leaves readers with the impression that China is an autocratic and belligerent country, which is contrary to the actual image of China: an advocate of peace. The word "aggressively" has double meanings: enterprising, and bellicose. On the one hand, it praises China's enterprising spirit; on the other hand, it criticizes China's belligerent attitude. Vagueness of words leaves readers with two choices of explanations.

The concordance lines of the word "COVID" from Corpus $\mathrm{N}$ show that the focuses of the COVID-19 pandemic are its impact, measures on it as well as outcomes on it. Through analyzing Table 3, several points can be concluded. Firstly, the COVID-19 pandemic has a great impact on many countries worldwide, which can be seen from sentences such as "engulfs Europe and the United States". Secondly, the newspaper does not believe in China's practice of fighting against COVID-19, and hasn't expected the positive outcome, but the result is incredible, which can be supported in the third and tenth line. Thirdly, the newspaper prefers putting China on the opposite side of western countries and comparing it with western countries, rather than regarding all countries as a community sharing a common destiny when fighting against disease, which is supported by the sentence in the first line "the contrast between the current state of the United States and China...

In the description stage, a table of 100 keywords and two tables of "China" and "COVID" concordance lines are established, and three points are summarized. Firstly, The New York Times regards China's outcome to fight against COVID-19 as unexpected, and praises China's efforts on protecting people. Secondly, attention is drawn to wide aspects of people and groups, among which, China's government gets more attention. Thirdly, China is put on the opposite side of western countries.

\subsection{Interpretation of Reports about China on the COVID-19 Pandemic}

Interpretation is the second stage of Fairclough's three-dimensional framework. In this section, news sources and reporting modes will be analyzed to deal with the process of text production.

\subsubsection{News Sources}

News sources can be classified into three categories: "specific sources, semi-specific 
sources and unspecific sources" ([2], p.93). As to the specific source, it refers to those who indicate elaborate information including the news provider's name, status and so on. The semi-specific source does not introduce detailed information about the source, but provides a vague message, for example, "experts say...”. As for the unspecific source, it applies when the detailed information is uncertain, for instance, "according to the report...". The statistical results of news sources in 35 news reports are shown in Table 4.

According to Table 4, specific source takes the largest proportion, which is $66.6 \%$, showing the objectivity of the newspaper to a certain extent. Semi-specific source accounts for the second largest proportion and the last one is the unspecific source, with $30.4 \%$ and $3.0 \%$ respectively. Some of the sentences employing semi-specific source and unspecific source may contain certain ideology. Here are three examples.

(1) Airline passengers must present negative antibody test results before boarding. Scientists consider it a largely useless way to curb disease transmission.

(2) Researchers have estimated that hundreds of thousands of people in China work part-time to post comments and share content that reinforces state ideology.

(3) With Mr. Xi's position secure, a dramatic shift in Chinese policy seems unlikely. He is expected to push for another five-year term as the Communist Party's leader, beginning in 2022, meaning his highly personalized rule could last another decade or more.

Example (1) shows the futility of the antibody test, and example (2) shows that some people in China are spreading the content of state ideology. "Scientists" and "researchers" in related fields have great authority and will guide readers to a great extent. However, if their identities are not clearly indicated, the existence of these judgments cannot be traced back, and there is a suspicion that The New York Times is using their identity to convey its views. In addition, the authenticity and credibility of these judgments still need to be further discussed. Scientists believe that antibody tests are largely useless. But in fact, the test results can really reflect whether people are infected to a certain extent, so as to exclude potential infected people. The statement of example (1) is relatively biased. There is no determiner or qualifier before "scientists", which may lead readers to mistakenly think that all scientists think so. If some scientists hold the opposite view, then this kind of expression is to guide readers and negate China's efforts. Example (3) is an example of the unspecific news source. The reporter indicates that Mr. Xi's governance is the "highly personalized rule". The idea is intensified

Table 4. News sources.

\begin{tabular}{ccccc}
\hline Source & Specific & Semi-specific & Unspecific & Total \\
\hline Total & 263 & 120 & 12 & 395 \\
Percentage & $66.6 \%$ & $30.4 \%$ & $3.0 \%$ & $100 \%$ \\
\hline
\end{tabular}


as it doesn't refer to the people who expect Mr. Xi to be the next term leader.

\subsubsection{Reporting Modes}

This section focuses on three reporting modes: direct speech, indirect speech and preset direct speech. Direct speech presents the speaker's words forthright with quotation marks. Indirect speech describes the speaker's words without quotation marks. As for preset direct speech, it contains both the features of indirect speech and that of direct speech. The sentence uses indirect speech at the beginning, and then turns to direct speech. It is possible for this kind of reporting mode to carry the ideology of journalists. By counting the reporting modes, the statistics results of 35 news about them are shown in Table 5 .

It can be seen from Table 5 that direct speech accounts for the largest percentage in news reports, which reflects the objectivity and authenticity of reports. In addition, indirect speech and preset direct speech also account for a large percentage of the news reports, which is easy for reporters to convey their views and attitudes. Here are some examples.

(4) Mr. Trump deflected blame, referring to the virus as the "China plague" and casting doubt on whether the official COVID-19 death tolls in China, Russia and India were accurate.

(5) Workers in another county boasted of their "severe crackdown" on what they called rumors: 16 people had been investigated by the police, 14 given warnings and two detained.

(6) Mr. Xi, by contrast, described China as a benevolent power that does not wish ill on anyone, without mentioning China's expansionist behavior in the South China Sea, mass detentions in Xinjiang, political repression in Hong Kong and warnings to Taiwan, the self-governing island that China's ruling Communist Party regards as Chinese territory.

(7) Offering no hint of contrition, Mr. Xi portrayed his nation of 1.4 billion people as having acted responsibly to combat COVID-19, the disease caused by the virus.

"China plague" implies that the virus belongs to China, and "severe crackdown" describes the degree of relevant measures. These words have double quotation marks in the text, which manifests that the reporter might disprove of the content of the speech, or they play an emphasis role, so as to indirectly present the position of journalists. The degree of "severe" varies in different people's eyes. Since it is a relatively negative adjective when it is used with "crackdown", it gives people who are hostile to China the trigger to go on hating China. Just emphasizing the word in the sentence leaves much room for people to interpret.

Table 5. Reporting modes.

\begin{tabular}{ccccc}
\hline Reporting modes & Direct speech & Indirect speech & Preset direct speech & Total \\
\hline Total & 203 & 183 & 54 & 440 \\
Percentage & $46.1 \%$ & $41.6 \%$ & $12.3 \%$ & $100 \%$ \\
\hline
\end{tabular}


Example (6) and example (7) represent the category of indirect speech. While presenting the speaker's words, the reporter adds its own opinions. In the example (6), when Mr. Xi says that China is benevolent, the reporter deliberately mentions that China's governance in some territories is "expansionist", despotic, and even rightless. In the example (7), "offering no hint of contrition" reflects that the reporter considers that China needs to be responsible for the outbreak of the COVID-19 pandemic, which brings people's dissatisfaction with COVID-19 to China.

In the stage of interpretation, an autocratic image is constructed and responsibility for COVID-19's outbreak is indicated to belong to China.

\subsection{Explanation of Reports about China on the COVID-19 Pandemic}

Discourse is seen as a part of social practice. In order to find out what the reporter wants to express, it is necessary to consider the institutional and societal context.

\subsubsection{Institutional Context}

In the United States, media coverage is free, and it is not controlled by individuals, organizations or institutions. However, this kind of freedom is relative.

The vast majority of American news media are market-oriented private companies. They mainly rely on commercial operations and compete fiercely for market share in order to obtain maximum profits ([14], p.31). Since the media is a commercial organization, news reports will be affected by commercial factors, such as the circulation of newspapers. The media's choice of high-quality reports will improve the attractiveness of newspapers, and the attractive content of reports will also correspondingly increase the amount of reading. At the same time, the ideology of the media arouses the readers' ideology. "A newspaper can exist only if it reflects the common thoughts and feelings of people." ([14], p.48) COVID-19 in China has gradually subsided, which is not the case in the United States, and the contrast between China and the US is likely to cause some anti-China forces anger. In the process of reporting, newspapers will probably take readers' feelings into consideration and cater to readers in order to increase circulation.

\subsubsection{Societal Context}

In the view of western countries, China, as a socialist country in the East, has an opposite relationship with the capitalist countries in the West. In addition, in the last century, China was poor and weak, with weak national strength and low international status. Nowadays, China's strength is growing day by day, and its international status is becoming more and more important, which threatens the dominant position of western countries, especially the superpower status of the United States. Therefore, the Chinese government is often deliberately discredited, which damages China's international image and reputation. Such ideology 
is also reflected in news reports. Besides, the media has a very close relationship with the government. Ostensibly, the media can evaluate and supervise the government, but in real life, the media's reports are affected by the government. The period from September to December of 2020 is the key time for US elections. Some politicians may attempt to attack China for their own interests, and throw the responsibility for the COVID-19 in the United States to China, which probably can be seen from the saying of "China plague".

Through analyzing from the explanation dimension, media's catering for readers deepens the thoughts and feelings of anti-China forces, and China's quick development arises some western counties feeling of threatening.

\section{Conclusions}

Through analyzing thirty-five news reports from September to December of 2020 in The New York Times, with Norman Fairclough's three-dimensional framework and the corpus analysis software AntConc, this thesis concentrates on China's image and media's ideology towards China in The New York Times, and finds three major points.

Firstly, The New York Times compliments China's outcome of fighting against COVID-19, but doesn't fully agree with the measures. Although it doesn't expect a positive result of China's fighting against the pandemic, it is astonished to find that the measures taken by China are effective. Besides, it praises China's efforts on protecting people. However, it doesn't approve the practice of the lockdown in China, saying it is effective but suffocating.

Secondly, The New York Times puts China on the opposite side of the United States and other western countries. The rapid development of China makes western countries feel threatened, and shakes the international situation dominated by the western countries to a certain extent, especially the United States. This threat probably has become a kind of consciousness, which is likely to lead the newspaper to put China on the opposite side of the western countries and discredit China. Although the result of China's fighting against the pandemic is shocking in such a stable situation from September to December, it still can not avoid criticism.

Thirdly, it regards China as a threatening and autocratic country to a certain extent. The newspaper focuses on the measures and results of the pandemic, and the treatment of the disease. In addition, the Chinese government is given a lot of attention, which is described as despotic and the governance is a kind of personalized rule. Besides, when describing China, some negative words, such as "manipulating" and "aggressively", are used to construct a relatively negative image of China. The different social cultures of the two countries, China's rising international status and the upcoming election of the United States all affect the choice of specific discourse by the media to a certain extent.

News reports are mixed with ideologies of reporters and media organizations, which also partly contain ideologies of the government. Through analyzing re- 
ports on China in The New York Times, this thesis hopes to help readers to treat the content of relevant reports critically, and to help maintain the image of China objectively.

Although an elaborate analysis is carried out, there are still some limitations. For one thing, the data only consists of 35 reports, which is not comprehensive and adequate. In order to draw a more authentic and more objective conclusion, more reports should be added if there is enough time. For another, the perspectives of the analysis can be further expanded such as to the viewpoint of transitivity, modality and so on.

\section{Significance}

The thesis is helpful to enrich the researches on news reports in the field of CDA, especially that about the COVID-19 pandemic. Besides, it helps to stimulate readers' critical thinking, helps them to objectively treat the construction of China's image in The New York Times, and helps them to find out the potential ideology, to understand news reports objectively when they read news coverage of COVID-19 about China. Lastly, as China develops rapidly, foreign media's attention follows. It is important to tell China's story well. This thesis also attempts to serve as a motive for journalists to establish a good image of China.

\section{Acknowledgements}

The authors would like to thank the National Social Science Fund of China (18CYY019) for the support in this research.

\section{Conflicts of Interest}

The authors declare no conflicts of interest.

\section{References}

[1] Liu, L.H. (2012) Discourse and Manipulation: Stories about China in the New York Times. Language and Communication, 3, 249-256. https://doi.org/10.1016/j.langcom.2012.04.002

[2] Zhou, R.Q. and Qin, S.Y. (2020) A Critical Discourse Analysis of News Reports on Sino-US Trade War in The New York Times. English Language Teaching, 13, 85-98. https://doi.org/10.5539/elt.v13n10p85

[3] Dong, Y. (2020) Discourse Analysis of the COVID-19 Pandemic in Public Discussions on Western Social Media from the Perspective of "Metaphor Reframing". Foreign Languages Research, 37, 36-42.

[4] Luporini, A. (2021) Metaphor, Nominalization, Appraisal: Analyzing Coronavirus-Related Headlines and Subheadings in China Daily and The Wall Street Journal. GEMA Online Journal of Language Studies, 21, 253-273. https://doi.org/10.17576/gema-2021-2101-15

[5] Chen, M.Z. and Xie, Q. (2020) Hedge Study on the COVID-19 Pandemic in Foreign Publicity News Reports: A Case Study of People's Daily. Journal of Hubei University of Economics (Humanities and Social Science), 17, 100-103.

[6] Ge, H.W. (2020) A Corpus-Based Discourse Analysis of Reports on COVID-19 Ep- 
idemic in China in the New York Times. Journal of Chongqing Jiaotong University (Social Sciences Edition), 20, 108-116.

[7] Chaiuk, T.A. and Dunaievska, O.V. (2020) Producing the Fear Culture in Media: An Examination on Coronavirus Discourse. Journal of History Culture and Art Research, 2, 184-194. https://doi.org/10.7596/taksad.v9i2.2636

[8] Sun, W.N. (2021) The Virus of Fear and Anxiety: China, COVID-19, and the Australian Media. Global Media and China, 6, 24-39. https://doi.org/10.1177/2059436421988977

[9] Feng, T.T. and Wang, F. (2020) Analysis of US Mainstream Media's Coverage about the COVID-19 Pandemic in China-A Case Study of The Wall Street Journal. Youth Journalist, 29, 102-103.

[10] Zhao, X.Y. (2021) Discourse Analysis of the COVID-19 Epidemic Reports in People's Daily. Media Forum, 4, 29-31.

[11] Fairclough, N. (1989) Language and Power. Longman, London.

[12] Ji, W.N. and Xin, B. (2009) On Fairclough's Theory of Critical Discourse Analysis. Foreign Language and Literature, 25, 21-25.

[13] Liu, W. (2020) The Critical Discourse Analysis of Sino-US Trade War News Reports Based on China Daily and the New York Times. M.A. Thesis, Shandong Agricultural University, Tai'an.

[14] Luo, J.L. (2013) The Orientation of American Media Reporting on China's News. Ph.D. Thesis, China University of Political Science and Law, Beijing. 